\title{
On the Stochastic Optimal Control Model of the Investments of Defined Contribution (DC) Pension Funds
}

\section{*LATUNDE, T; ESAN, OO; RICHARD, JO; DARE, DD}

\author{
Department of Mathematics, Federal University Oye-Ekiti, Nigeria, \\ * Corresponding Author Email: tolulope.latunde@fuoye.edu.ng.
}

\begin{abstract}
One of the major problems faced in the management of pension funds and plan is how to allocate and control the future flow of contribution likewise the proportion of portfolio value and investments in risky assets. In this work, optimal investment for a stochastic model of a Defined contribution (DC) is investigated such that the model design is analysed yielding an optimized expected utility of the members' terminal wealth. An optimized solution is derived using the Hamilton Jacobi equation in solving the problem of investment strategy formulated by Constant absolute risk aversion (CARA). However, to consider the changes that occur in the dimension of optimal solutions in optimization problems, mostly, the optimal behaviour of parameters, the sensitivity analysis is considered. Thus, the analysis of the model is carried out herein by utilising the approach of the sensitivity analysis of parameters. This is carried out by using Maple software and varying the values of some model parameters such that the behaviour of each parameter relating to the pension funds invested in the risky assets is determined. The results are presented graphically and using tables thus discussed such that pension investors and stakeholders are advised.
\end{abstract}

DOI: https://dx.doi.org/10.4314/jasem.v24i2.12

Copyright: Copyright (C) 2020 Latunde, et al. This is an open access article distributed under the Creative Commons Attribution License (CCL), which permits unrestricted use, distribution, and reproduction in any medium, provided the original work is properly cited.

Dates: Received: 16 November 2019; Revised: 11 January 2020; Accepted: 22 February 2020

Keywords: Stochastic; DC Pension funds; Sensitivity analysis; Hamilton-Jacobi-Bellman equation; Optimal investment

The management of pension funds has transformed in the recent years from DB pension systems where the employer alone used to contribute to defined contributory pension schemes where both the employer and the employee must contribute a given percentage towards the fund. The main sponsor of a pension fund is the employer, such as companies, public corporations, industry or trade groups; accordingly, employers, as well as employees, typically contribute. Funds may be internally or externally managed. Returns to members of pension plans backed by such funds may be purely dependent on the market or maybe overlaid by a guarantee of the rate of return by the sponsor. The latter have insurance features in respect of replacement ratios subject to the risk of bankruptcy of the sponsor, as well as the potential for risk transfers between older and younger beneficiaries, which are absent in defined contribution funds. DC pension schemes are merged into one pension plan to study the impact of the voluntary contributions on the pension fund invested in the risky asset. The result is that there is considerable uncertainty over the amount of pension that might be achieved at the time of retirement. This is in contrast to a DB pension which delivers a well-defined level of pension. A DC pension plan is a personal pension which offers additional flexibility over occupational schemes through variation of the contribution rate which implied that a pension fund member might choose to pay more if their pension fund investments have not been performing very well. Defined contribution problems typically deal with the case where the terminal utility is a function of the fund size at retirement. The case where the terminal utility is a function of pension purchased at retirement (i,e., fund divided by annuity rate) in a stochastic interest-rate environment is been considered in this work. For any class of the fund, the liability is in real (inflationadjusted) terms. This is because the objective of asset management is to attain a high replacement ratio at retirement which is itself determined by the growth rate of average earning. Defined contribution plans have tended to grow faster than defined benefit in recent years, as employers have sought to minimise the risk of their obligations, while employees seek funds that are readily transferable between employers. Kinds of literature on defined contribution problems may typically deal with the case where the terminal utility is a function of the fund size at retirement, see Merton (1969, 1971) and Deelstra et al. (2003). The case where the terminal utility is a function of pension purchased at retirement (fund divided by annuity rate) in a stochastic interest-rate environment has been considered by Cairns et al. (2006). The stochastic methodology is mainly based on solving the HamiltonJacobi-Bellman (HJB) equation, from the dynamic programming under the real-world probability measure. Several authors have laid down theories related to the stochastic control approach. For instance, Vigna and Haberman (2001) used stochastic dynamic programming to analyse the financial risk in a defined contribution (DC) pension scheme, their attempt is to find an optimal investment strategy, Xiao et al. (2007) applied CEV model to derived two 
explicit solutions for the logarithm utility function with two different periods (before and after retirement) in a DC pension fund using Legendre transformation method. optimal investment strategies in a DC pension with multiple contributors using power transformation method. Some utility functions such as constant relative risk aversion (CRRA) and constant absolute risk aversion (CARA) Battocchio and Menoncin (2004), have been used to study optimal investment strategies. However, to consider the changes that occur in the dimension of optimal solutions especially to the real-life problem, the sensitivity analysis of parameter is considered as a good tool. Most times, to obtain the optimal solution, it is always necessary to understand the behaviours of model parameters to optimise the problem's solution by varying the values of each parameter or data used, Rao (2009). Some experts have carried out researches on the sensitivity analysis to ascertain the behaviour of parameters in the formulation of the model such as in control problem of management of assets, transportation problems, and the result was applied to the pension scheme in Croatia, Latkovic and Liker (2000). Latunde et al. (2016), Latunde and Bamigbola (2018), Latunde et al. (2019), Latunde et al. (2020) also worked in the utilisation of sensitivity analysis to real-life problems. Thus, in this work, the approach of sensitivity analysis of some model parameters are considered to characterize the model and optimize the model solution.

\begin{tabular}{|c|c|}
\hline Variables \& Parameters & Definition \\
\hline $\bar{P}$ & Probability space \\
\hline$B(t)$ & $\begin{array}{l}\text { Standard dimensional } \\
\text { motion }\left[B_{0}(t), B_{1}(t)\right]\end{array}$ \\
\hline$Y_{t}$ & $\begin{array}{l}\text { Amount given to the } \\
\text { retired contribution } \\
\text { (positive) }\end{array}$ \\
\hline$F$ & $\begin{array}{l}\text { filtration generated by } \\
\text { Brownian motion }\end{array}$ \\
\hline$d R(t)$ & $\begin{array}{l}\text { Dynamics of the surplus } \\
\text { investment }\end{array}$ \\
\hline$H_{0}(\mathrm{t}), H_{0}(\mathrm{t})$ & $\begin{array}{l}\text { risk-free asset and risky } \\
\text { asset }\end{array}$ \\
\hline$\alpha$ & $\begin{array}{l}\text { Expected return of the } \\
\text { risky asset }\end{array}$ \\
\hline$\beta$ & instantaneous volatility \\
\hline$M$ & $\begin{array}{l}\text { Additional voluntary } \\
\text { contribution }\end{array}$ \\
\hline$\eta$ & $\begin{array}{l}\text { Pension fund invested in } \\
\text { the risky asset }\end{array}$ \\
\hline$X$ & $\begin{array}{l}\text { Wealth of the pension } \\
\text { fund }\end{array}$ \\
\hline$N$ & Marginal utility investor \\
\hline$T$ & Retirement time \\
\hline
\end{tabular}

Model Formulation: Let the market be of a risk-free asset (cash) and a risky asset (stock). Suppose $(\Omega, F, P)$

$$
d R(t)=d M-d Y(t)=\lambda y_{0} d t+m_{0} d B_{0}+y_{1} d B_{1}(t)
$$

Hamilton-Jacobi-Bellman (HJB) Equation: Let $\boldsymbol{\eta}$ be the strategy and we define the utility attained by the 
members from a given state at a time $t$ as

$U_{\eta}(t, q, x)=G \eta[N(X(T)) \mid q(t)=q, X(t) X]$

where $q$ is the short interest rate and $x$ is the wealth. The aim of this section is to find the optimal value function and optimal strategy given as

$U(t, q, x)=\sup _{\eta} U_{\eta}(t, q, x)$

and $\eta^{*}$ Respectively such that

$U_{\eta^{*}}(t, q, x)=U(t, q, x)$

Stochastic Formulation of wealth: Let $\boldsymbol{X}(\boldsymbol{t})$ denote the wealth of pension fund at $\mathrm{d}[\mathbf{0}, \boldsymbol{T}]$, let $\boldsymbol{\eta}$ denote the proportion of the pension fund invested in the risky asset $\boldsymbol{X}_{\boldsymbol{t}}$ and $\mathbf{1}-\boldsymbol{\tau}$, the proportion invested in risk-free asset hence the dynamics of the pension wealth is given by

$\left\{d X(t)=\eta X\left(t \frac{d H_{t}(t)}{H_{t}(t)}+(1-\eta) X(t) \frac{d H_{0}(t)}{H_{0}(t)}+d R(t)_{X(0)=x_{0}}(9)\right.\right.$

and then by Substituting (1) and (2) into (5), we obtain

$d X(t)=\left[(\eta X(t)(\alpha-q))+q X(t)+\lambda y_{0}\right] d t+\left(X(t) \eta \beta+m_{0}\right) d B_{0}(t)+y_{1} d B_{1}(t)$

The HJB equation from (6) $U_{t}+\alpha h U_{h}+\left(q x+\lambda y_{0}\right) U_{b}+\frac{1}{2} \beta^{2} h^{2} U_{h h}+\frac{1}{2} y_{1}^{2} U_{x x}+\sup \left\{\frac{1}{2}\left(b \eta \beta+m_{0}\right)^{2} U_{x x}\right.$

$\left.+\eta x(\alpha-q) U_{x}+\eta x \beta^{2} h U_{x h}\right\}=0$.

Differentiate (11) with respect to $\eta$, the result shows the first order maximizing condition ;

$m_{0} \beta U_{x}+\eta x^{2} \beta^{2} U_{x x}+x \beta^{2} h U_{x h}+x(\alpha-q) U_{x}=0$

solving (12) for $\eta$ in (11) we have

$\eta^{*}=-\frac{\left[m_{0} \beta U_{x x}+(\alpha-q) U_{x}+\beta^{2} h U_{x h}\right]}{b \beta^{2} U_{x x}}$

equating (13) into (11), we obtain $U_{t}+\alpha h U_{s}+\left(q x+\lambda y_{0}\right) U_{x}+\frac{1}{2} \beta^{2} h^{2} U_{x x}+\frac{1}{2} y_{1}{ }^{2} U_{x x}$

$$
\begin{gathered}
+\sup \left\{\frac{1}{2}\left(-x \beta \frac{\left[m_{0} \beta U_{x x}+(\alpha-q) U_{x}+\beta^{2} h U_{x h}\right]}{x \beta^{2} U_{x x}}+m_{0}\right)^{2} U_{x x}\right. \\
-\frac{\left[m_{0} \beta U_{x x}+(\alpha-q) U_{x}+\beta^{2} h U_{x h}\right]}{x \beta^{2} U_{x x}} x(\alpha-q) U_{x} \\
\left.-\frac{\left[m_{0} \beta U_{x x}+(\alpha-q) U_{x}+\beta^{2} h U_{x h}\right]}{x \beta^{2} U_{x h}} x \beta^{2} h U_{x h}\right\}=0
\end{gathered}
$$

so that $U_{t}+\alpha h U_{h}+\left(q x+\lambda y_{0}-\frac{m_{0}(\alpha-q)}{\beta}\right) U_{x}+\frac{1}{2} \beta^{2} h^{2}\left[U_{h h}-\frac{U_{x h}{ }^{2}}{U_{x x}}\right]+\frac{1}{2} y_{1}{ }^{2} U_{x x}$

$-\frac{(\alpha-q)^{2}}{2 \beta^{2}} \frac{U_{x}^{2}}{U_{x x}}-(\alpha-q) h \frac{U_{x} U_{x h}}{U_{x x}}=0$

where $U(T, h, x)=N(x)$ and $N(X)$ is denoted as the marginal utility of the investor. We then consider solving (15) for $U$, substituting into (13) using power transformation and change of variable technique.

Optimal Investment Strategy with Exponential Utility Function: Suppose the member takes an exponential utility

$N(b)=-\frac{1}{k} e^{-k x}, k>0 . \quad(16)$

LATUNDE, T; ESAN, OO; RICHARD, JO; DARE, DD 
The ultimate risk aversion of a decision-maker with the utility in (16) above is constant and is a CARA utility, we then interpret a solution of (15) with the form :

$\left\{\begin{array}{l}U(t, h, x)=-\frac{1}{k} e^{[-k[v(t)(x-E(t))+z(t, h)]} \\ Z(T, h)=0, v(T)=1, E(T)=0\end{array}\right.$

$U_{t}=-k U\left[v_{t}(x-E(t))-v d_{t}+z_{t}\right]$

$\left.U_{h}=-k U z_{h}, U_{x}=-k v U, U_{x x}=k^{2} v^{2} U, U_{h h}=\left(k^{2} z^{2}-k z_{h h}\right) U, U_{h b}=k^{2} v z_{h} U\right\}$

From (15), (17) and (18), the result is obtained, $\left[V_{t}+v q\right] z+\left[\lambda y_{0}-\frac{m_{0}(\alpha-q)}{\beta}-\frac{v_{t}}{v} E-E_{t}-\frac{1}{2} x_{1}{ }^{2} k v\right] v$

$\left.+z_{t}+q h z_{h}+\frac{1}{2} \beta^{2} h^{2} z_{h h}+\frac{(\alpha-q)^{2}}{2 k \beta^{2}}\right]=0$

the following equation is obtained from (19)

$v_{t}+q v=0$

$\lambda y_{0}-\frac{m_{0}(\alpha)-q}{\beta}-\frac{v_{t}}{v} x-x_{t}-\frac{1}{2} k x_{1}^{2} v=0$

$z_{t}+q h z_{s}+\frac{1}{2} \beta^{2} h^{2} z_{h h}+\frac{(\alpha-q)^{2}}{2 k \beta^{2}}=0$

Equation(20) gives

$v(t)=e^{q(R-r)}$

by solving equations (20),(21), and (23)

$E_{t}-q E=\lambda y_{0}-\frac{m_{0}(\alpha-q)}{\beta}-\frac{1}{2} k E_{1}{ }^{2} e^{q(R-r)}$

the above equation implies (24)

$E(t)=\frac{\left(e^{-q(R-r)}-1\right)}{2 q}\left(\lambda y_{0}-\frac{m_{0}(\alpha-q)}{\beta}\right)+\frac{k y_{1}{ }^{2}\left(e^{q(R-r)}-1\right)}{4 q}$

$\left\{_{P(t, h)=P(t)+W(t) \beta^{2}}^{Z}\right.$

$\left\{\begin{array}{l}Z(t)=0, W(T)=0, \beta^{2}=x^{2} h^{2 e} \\ P(T)\end{array}\right.$

$z_{t}=P_{t}+W_{t} h^{2 e}, z_{h}=\frac{-2 \epsilon W y^{2}}{h \beta^{2}}, z_{h h}=\frac{2 \epsilon(2 \epsilon+1) W x=y^{2}}{h^{2} \beta^{2}}$

putting (27) into (22),

$P_{t}+2 \epsilon(2 \epsilon+1) W y^{2}+\frac{1}{\beta^{2}}\left(W_{t}-2 q \epsilon W y^{2}+\frac{(\alpha-q)^{2}}{2 k}\right)=0(28)$

$W_{t}-2 q \epsilon W y^{2}+\frac{(\alpha-q)^{2}}{2 k}=0$

$P_{t}+2 \epsilon(2 \epsilon+1) W y^{2}=0$

By make $\mathrm{W}$ the subject of the formula,

$W_{t}-2 q \epsilon W y^{2}+\frac{(\alpha-q)^{2}}{2 k}=0$

$W(t)=\frac{(\alpha-q)^{2}}{4 q \epsilon k x^{2}}\left[1-e^{2 q \epsilon(t-T)}\right]$

substituting (31) into (29) and then solving it, 
$P(t)=\frac{(2 \epsilon+1)(\alpha-q)^{2}}{4 q k}$

substituting (31) into (29) and then solving it,

$P(t)=\frac{(2 \epsilon+1)(\alpha-q)^{2}}{4 q k}\left[\frac{1}{2 q \epsilon}\left(e^{2 q \epsilon(t-T)}-1\right)+(T-t)\right]$

$z(t, h)=P(t)+W(t) \beta^{2}(35)$

$Z(t, h)=\frac{(2 \epsilon+1)(\alpha-q)^{2}}{4 q k}\left[\frac{1}{2 q \epsilon}\left(e^{2 q \epsilon(t-T)}-1\right)+(T-t)\right]+\frac{(\alpha-q)^{2}}{4 q \epsilon k y^{2}}\left[1-e^{2 q \epsilon(t-T)}\right] \beta^{2}$

From equation (34) and (13), The optimal investment strategy with stochastic additional contribution is given below

$\eta *=\frac{1}{x k \beta^{2}}\left\{(\alpha-q) e^{q(t-T)}\left[1+\frac{(\alpha-q)}{2 q}\left(1-e^{2 q \epsilon(t-T)}\right)\right]\right\}-\frac{m_{0}}{x \beta}$

Also when we assume that when there is no voluntary contribution i.e $m_{0}=0$, then we reduce the stochastic additional contribution to ;

$\eta *=\frac{1}{x k \beta^{2}}\left\{(\alpha-q) e^{q(t-T)}\left[1+\frac{(\alpha-q)}{2 q}\left(1-e^{2 q \epsilon(t-T)}\right)\right]\right\}$

\section{RESULTS AND DISCUSSION}

Several numerical simulations have been carried out in order to investigate some quantities of interest to the pension fund member when the model is implemented in the practice using Maple software. The following parameters are used in the simulations to check the parameter sensitivity analysis in the model design; $\alpha$ $=0.05, k=0.3, T=40, q=0.05, \beta=2, \epsilon=-2$, $m_{0}=2, x_{0}=2$, and $t=5$. It is observed from Figure 1 that the expected return of the risky asset $\alpha$ increases with respect to the pension fund in the risky asset $\eta *$ which implies that the expected return of the risky asset and optimal pension fund investments are directly proportional to each other.

Figure 2 shows that the Retired contribution $k$ decreases uniformly until when the value of Pension fund invested in the risky asset $\eta *$ is 0.5 , where the retired contribution is now stable as such, the retired contribution will be stable when it is 0.5 against when the Pension fund invested in the risky asset is 0.5 .

Figure 3 shows that the Retirement time $T$ is uniformly stable everywhere against the Pension fund invested in the risky asset $\eta *$. Therefore the Pension fund invested in the risky asset $\eta *$ is stable with time. Figure 4 shows that the short interest rate q decreases until its 0.01 and 0.02 of the Pension fund invested in the risky asset $\eta *$ will decrease as wealth $x$ decreases and increase as wealth $\mathrm{x}$ increases, we can conclude that the higher the money invested by the investor, the higher the pension fund invested in the risky asset $\eta *$.

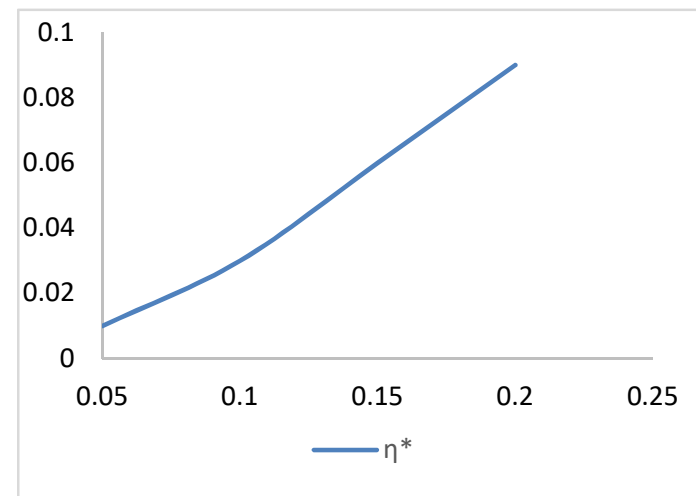

Fig 1: Expected return of risky asset $\alpha$ vs Pension fund invested in

the risky asset $\eta *$

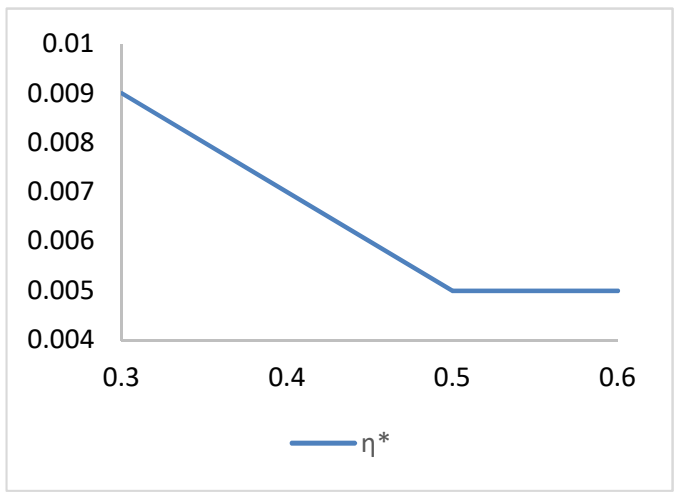

Fig 2: Retired contribution $k$ vs Pension fund invested in the risky asset $\eta *$ 


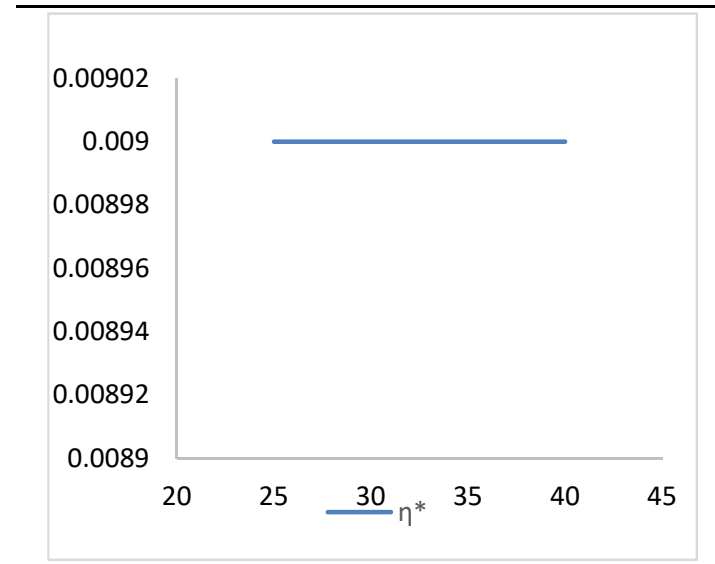

Fig 3: Retirement time $T$ vs Pension fund invested in the risky asset $\eta *$

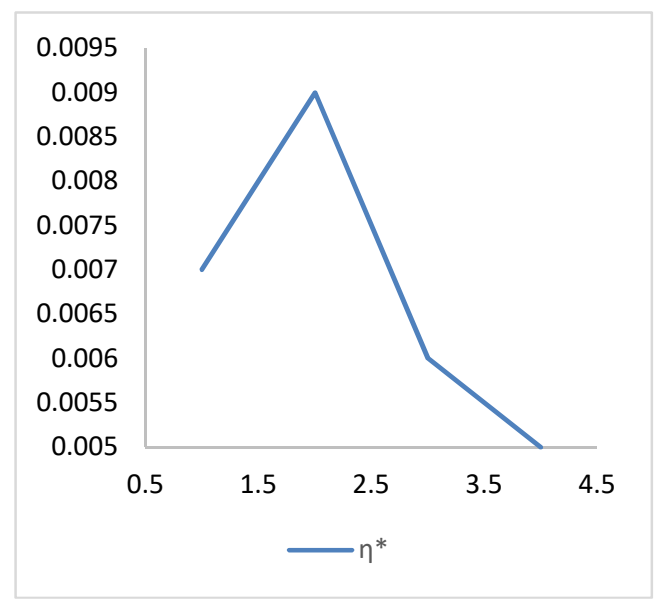

Fig 4: Short interest rate $q$ vs Pension fund invested in the risky

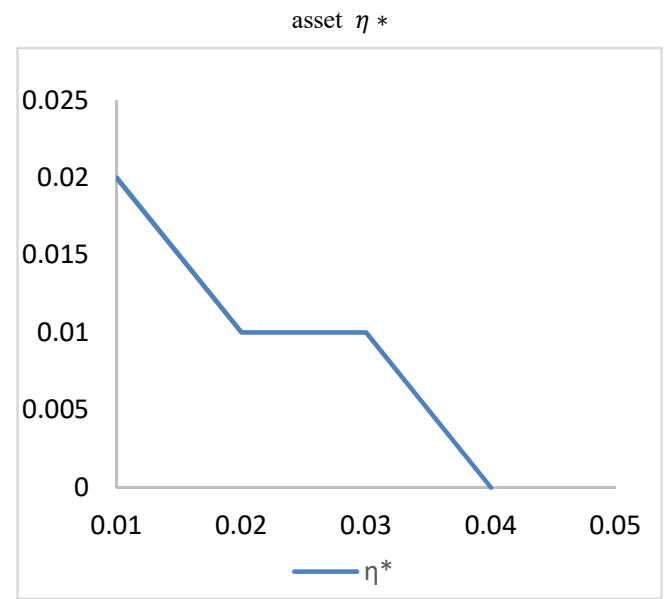

Fig 5: Instantaneous Volatility $\beta$ vs Pension fund invested in the risky asset $\eta *$

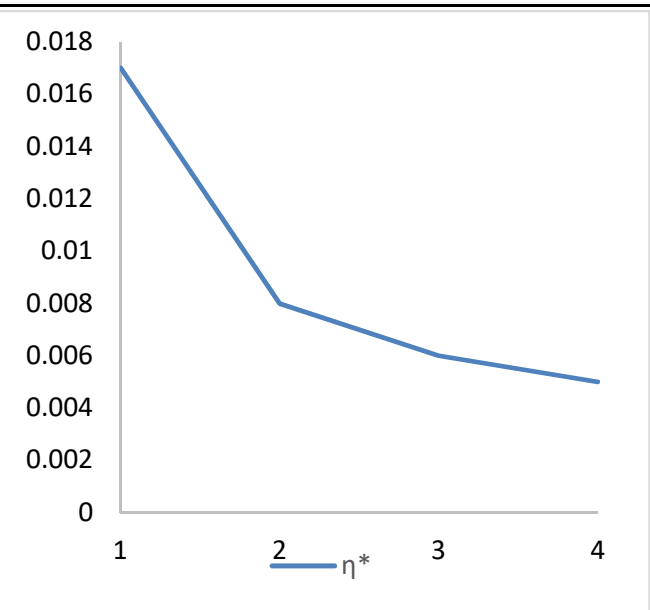

Fig 6: Wealth $X$ vs Pension fund invested in the risky asset $\eta *$

Figure 5 identifies the relationship between the instantaneous volatility $\beta$ and the pension fund invested in the risky asset $\eta *$. This changes direction inversely when the value of pension fund invested in risky asset $\eta *$ is at the maximum. Figure 6 represents the behaviour of the wealth $X$ with the pension fund invested in the risky asset $\eta *$ showing that increases in the net worth do not automatically determine or corresponds directly with the rate at which the risky asset of pension fund $\eta *$ can be invested.

Conclusion: In this research work, Stochastic optimal control for DC pension funds was analysed as an advancement of Akpanibah and Oghene'Oro (2018). An optimized problem is derived using HamiltonJacobi equation in solving the optimal investment strategy where the Constant absolute risk aversion (CARA) was used to study the optimal investment strategies and maximize the expected utility of the investors' terminal wealth. The analysis showed some relationships of the model parameters and how changes in some different types of parameters could determine the behaviours of the model in general and aid optimal solutions.

\section{REFERENCE}

Akpanibah, EE, Oghene'Oro, O (2018). Optimal portfolio selection in a DC pension with multiple contributors and the impact of stochastic additional voluntary contribution on the optimal investment strategy. Int. J. Math. Comput. Sc. 12(1): 14-19.

Battocchio, P; Menoncin, F (2004). Optimal pension management in a stochastic framework. Insur. 34(1): 79-95.

Cairns, AJG; Blake, D; Dowd, K (2006). Stochastic life-styling: optimal dynamic asset allocation for defined contribution pension plans. J. Econ. Dyn. Control 30(5): 843-877. 
Deelstra, G; Grasselli, M; Koehl, PF (2003). Optimal investment strategies in the presence of a minimum guarantee. Insur. 33(1): 189-207.

Latunde, T; Esan, OO; Richard, JO; Dare, DD (2020). Analysis of a stochastic optimal control for pension fund management and application to investments in lower middle-income countries. $J$. Niger. Society Phys. Sci. 2(1): 1-6.

Latunde, T; Richard, JO; Esan, OO; Dare, DD (2019). Sensitivity of parameters in the approach of linear programming to a transportation Problem of an optimal control model for capital asset management. J. Niger. Society Phys. Sci. 1(3): 116-121.

Latunde, T; Bamigbola, OM; Aderinto, YO (2016). Sensitivity of parameters in an optimal control model of the electric power generating system. Ilorin J. Comput. Sci. Inf. Technol. 1: 54-70.
Latunde, T; Bamigbola, OM (2018). Parameter estimation and sensitivity analysis of an optimal control model for capital asset management. $A d v$. Fuzzy Syst. 2018: 1-11.

Merton, RC (1969). Lifetime portfolio selection under uncertainty: The continuous time case. Review Econ. Statistics 51(3): 247-257.

Merton, RC (1971). Optimal consumption and portfolio rules in a continuous time model. $J$. Econ. Theory 3: 373-413.

Rao, SS (2009). Engineering optimization Theory and Practice. Hoboken, New Jersey: John Wiley \& Sons, Inc.

Vigna, E; Haberman, S (2001). Optimal investment strategy for defined contribution pension schemes. Insur.: Math. Econ. 28: 233-262.

Xiao, J; Hong, Z; Qin, C (2007). The constant elasticity of variance (CEV) model and the Legendre transform-dual solution for annuity contracts. Insur. 40(2): 302-310. 